\title{
Activated peripheral lymphocytes with increased expression of cell adhesion molecules and cytotoxic markers are associated with dengue fever disease
}

\author{
Elzinandes L Azeredo, Sonia MO Zagne**, Allan R Alvarenga, Rita MR Nogueira, \\ Claire F Kubelka, Luzia M de O liveira-Pinto*/+
}

Laboratório de Imunologia Viral, Departamento de Virologia *Laboratório de Auto-imunidade e Imuno-regulação, Departamento de Imunologia, Instituto Oswaldo Cruz-Fiocruz, Av. Brasil 4365, 21045-900 Rio de Janeiro, RJ, Brasil **Departamento de Clínica Médica, Hospital Universitário Antônio Pedro, Universidade Federal Fluminense, Niterói, RJ, Brasil

The immune mechanisms involved in dengue fever and dengue hemorrhagic/dengue shock syndrome are not well understood. The ex vivo activation status of immune cells during the dengue disease in patients was examined. CD4 and CD8 T cells were reduced during the acute phase. Interestingly, CD8 T cells co-expressing activation marker $H L A-D R, Q, P$, and cytolytic granule protein-Tia-1 were significantly higher in dengue patients than in controls. Detection of adhesion molecules indicated that in dengue patients the majority of T cells (CD4 and CD8) express the activation/memory phenotype, characterized as $C D 44^{H I G H}$ and lack the expression of the naïve cell marker, $C D 62 L^{L O W}$. Also, the levels of T cells co-expressing ICAM-1 (CD54), VLA-4, and LFA-1 (CD1la) were significantly increased. CD8 T lymphocytes expressed predominantly low levels of anti-apoptotic molecule Bcl-2 in the acute phase, possibly leading to the exhibition of a phenotype of activated/effector cells. Circulating levels of IL-18, TGF- $\beta 1$ and sICAM-1 were significantly elevated in dengue patients. Early activation events occur during acute dengue infection which might contribute to viral clearance. Differences in expression of adhesion molecules among CD4 and CD8 T cells might underlie the selective extravasation of these subsets from blood circulation into lymphoid organs and/or tissues. In addition, activated CD8 T cells would be more susceptible to apoptosis as shown by the alteration in Bcl-2 expression. Cytokines such as IL-18, TGF- $\beta 1$, and sICAM-1 may be contributing by either stimulating or suppressing the adaptative immune response, during dengue infection, thereby perhaps establishing a relationship with disease severity.

Key word: dengue - patients lymphocytes activation

Approximately 1 billion human infections with dengue virus (DENV) are estimated to occur annually. The majority of these cases develop mild self-limited dengue fever (DF), whereas only a small proportion develop severe hemorrhagic manifestations, dengue hemorrhagic fever/dengue shock syndrome (DHF/DSS), at the end of the acute phase of illness. DHF is a severe febrile disease characterized by abnormalities in homeostasis and increased vascular permeability, which may result in DSS as reviewed by Rothman (2004).

There is a correlation between viral load and disease severity (Vaughn et al. 2000). In this way, immunity to a given dengue virus serotype (DENV 1, DENV 2, DENV 3, and DENV 4) provides good protection against re-infection by that same serotype, however subsequent infection by other viral serotypes markedly increases the risk of DHF/DSS, contributing to the hypothesis by the $\mathrm{Ab}$ (antibody) mediated enhancement of infection (Thein et al. 1997). In conjunction to the role of Abs in immunopathogenesis of dengue infection, a mechanism of mo-

Financial support: CNPq, Faperj, IOC-Fiocruz +Corresponding author: lpinto@ioc.fiocruz.br Received 8 March 2006

Accepted 3 May 2006 lecular mimicry has recently been proposed, in which Abs directed against the DENV non-structural protein (NS1) cross-react with endothelial cells, resulting in endothelial cells activation, increased levels of cytokine, chemokine, and adhesion molecule expression and consequently PBMC adhesion to endothelial cells. This activation may favour the vasculopathy observed in DENV infection via the transcription factor NF- $\mathrm{kB}$ (Lin et al. 2005).

Immune response to DENV infection may also underlie the pathogenesis of disease. In this context, a shift from a Th1-type cytokine response in DF to a Th2-type cytokine response in DHF has been correlated with increasing severity of the illness (Chaturvedi et al. 1999). Among cytokines, tumour necrosis factors- $\alpha$ (TNF- $\alpha$ ), interleukin-6 (IL-6), IL-10 (Iyngkaran et al. 1995, Azeredo et al. 2001) and more recently, transforming growth factor$\beta 1$ (TGF- $\beta 1$ ) (Agarwal et al. 1999) and macrophage migration inhibitory factor (MIF) (Chen et al. 2006) are frequently associated with severity and platelet decay (Green et al. 1999b, Azeredo et al. 2001). Elevated levels of soluble TNF$\alpha$ receptors, soluble CD8, and soluble IL-2 receptor (Green et al. 1999b), and soluble VCAM-1 (vascular cell adhesion molecule 1) (Murgue et al. 2001) have been reported in plasma or serum of DHF patients compared to the levels found in early course infection DF patients. However, a rise in cytokines and soluble receptors is an indirect measurement of immune activation not revealing which immune cells are activated. Thus, the percentage CD8 T and 
NK cells expressing CD69 rose more in children who developed DHF than in those with only DF, demonstrating that cellular immune activation is present early in acute dengue and is related to disease severity (Green et al. 1999a). More recently, our group demonstrated that peripheral NK and NKT cells rates are increased in adult Brazilian mild dengue patients. The majority of these NK cells display early markers for activation (CD69, HLA-DR, and CD38), cell adhesion molecules (CD44, CD11a) besides the intracellular cytotoxic granule, Tia-1 (Azeredo et al. 2006). A study displayed that during acute infection few DENV-specific T cells of low affinity for the infecting virus were recovered in Thai children, contributing to higher viral loads and increased immunopathology (Mongkolsapaya et al. 2003). Impaired proliferation of T cells to a wide variety of stimuli, specific or not, was suppressed during acute dengue infection in subjects with either DHF (Mathew et al. 1999) or DF (Mathew et al. 1999, Azeredo et al. 2001). Nevertheless, these investigations have not fully elucidated the complex mechanisms of immunopathology during DENV infection.

Thus, in adult Brazilian dengue patients, we determined the ex vivo activation status of immune cells over the period of acute to convalescence infection. Most activation markers studied were induced in CD8 lymphocytes during acute phase, returning to normal expression on convalescence, showing the prevalence of this cell response over CD4 cell during infection. Moreover, in an attempt to better understand how it correlates with disease severity, we observed that some of these activation markers were more pronounced in CD8 cells among severity of DF cases.

\section{MATERIALS AND METHODS}

Study population and blood samples - From 2001 to 2002 the DENV 1 and 3 outbreak, heparinized peripheral blood samples were obtained from 60 dengue infected patients ( 35 females, 25 males, age range $15-73$ years), and among those a follow-up blood samples was obtained from 18 dengue infected patients, attended at two health centres in Niterói, state of Rio de Janeiro (Posto de Saúde de Itaipu and Centro Previdenciário de Niterói). All patients presented clinical diagnosis of dengue infection according to the criteria of the World Health Organization (WHO 2002). Among the dengue patients, 16 cases were hospitalised due to severity but, upon subsequent independent review of the medical record, only two of them were considered to meet all criteria for DHF. There was not one fatal case in this outbreak. Fifteen healthy individuals with similar age range ( 9 females, 6 males, age range 18-50 years), without any febrile or other illnesses in the previous three months, were included as controls.

A detailed physical examination was performed to detect hemorrhagic manifestations (positive tourniquet test for capillary fragility, skin haemorrhages, epistaxis, gingi$\mathrm{val}$, gastrointestinal or urinary tract haemorrhage), signs of plasma leakage (pleural or pericardial effusion, ascites), signs of circulatory failure (cold extremities, cyanosis, hypotension, tachycardia), and hepatomegally. Informed consent was obtained from all patients or their guardians prior to blood collection.
The diagnosis of DENV infection was confirmed by anti-dengue enzyme-linked immunoassorbent assay (ELISA)-IgM, serotype specific reverse trancription-polymerase chain reaction (RT-PCR), or by virus isolation. Dengue viral isolations were attempted from serum samples of patients in the acute phase, using Aedes albopictus $\mathrm{C} 6 / 36$ cell line. Isolates were demonstrated by immunofluorescence assay. Alternatively, virus was antigenically detected in monocytes by flow cytometry (Neves-Souza et al. 2005) in 23 out of 35 patients from 1-10 days after disease outset but not after 11 days. Dengue immune response was considered as primary or secondary by IgG ELISA according to previously established criteria.

For these studies, 76 samples were considered to be an acute sample up to study day 1 to 10 from the patients had at least one of the following symptoms: fever, headache, rash, myalgia, retro-orbital pain, arthralgia, and others symptoms associated or not with haemorrhagic manifestations, particularly, petechiae and tourniquet-positive test. Convalescent samples were obtained from other 12 patients 11 days or later after their onset disease. The subjects in convalescence phase were not febrile neither had others characteristics symptoms at that time.

As other investigators have previously reported (Harris et al. 2000, Phuong et al. 2004, Wilder-Smith \& Schwartz 2005) we also were unable to meet WHO criteria (WHO 2002) for severity classification. Indeed in Nicaragua, Harris et al. (2000) defined a severe patient group with signs of shock that do not fit DHF/DSS classification therefore designating a new disease category: dengue with signs associated with shock. More recently, Balmaseda et al. (2005) confirmed that strict application of the WHO criteria fails to detect a significant number of patients with severe manifestations of dengue, especially in adults in Nicaraguan hospitals. We considered all patients with thrombocytopenia $\left(<100,000\right.$ counts $\left./ \mathrm{mm}^{3}\right)$ and hypotension (postural hypotension with decrease in systolic arterial pressure in $20 \mathrm{mmHg}$ in supine position or systolic arterial pressure $<90 \mathrm{mmHg}$ ) as severe cases. Based on clinical grounds, we established that among dengue patients, 31 had platelet levels $\geq 100.000$ counts $/ \mathrm{mm}^{3}$, without hypotension and were classified as mild dengue; 19 other patients had thrombocytopenia and hypotension, successively receiving parenteral hydration for at least $6 \mathrm{~h}$ and were classified as severe dengue (due to not meeting classical DHF/DSS classification). Ten other patients had thrombocytopenia but had no other severe manifestation.

The procedures performed during this work were approved by the Ethics Committee of the Oswaldo Cruz Foundation, Brazilian Health Ministry (recognized by the Brazilian National Ethics Committee) under number 111/00.

Purification and cryopreservation of human peripheral blood mononuclear cells (PBMCs) - PBMCs from healthy individuals and dengue infected patients were obtained from $30 \mathrm{ml}$ of heparinized venous blood. Blood samples were diluted 1:1 with culture medium RPMI 1640 (Sigma) and PBMC were separated by performing Hystopaque $^{\mathrm{TM}}($ Sigma $)(\mathrm{d}=1077 \mathrm{~g} / \mathrm{ml})$ and centrifuged at $400 \mathrm{~g}$ 
for $30 \mathrm{~min}$. The PBMC layer was washed twice in RPMI 1640 medium. The viability of PBMC was greater than 95\% after Trypan blue exclusion. Approximately $10^{7}$ PBMCs were re-suspended in $1 \mathrm{ml}$ of solution destined for freezing [90\% inactivated FBS (Gibco Invitrogen Co.) plus $10 \%$ DMSO (Sigma)] and stored initially at $-70^{\circ} \mathrm{C}$ for $24 \mathrm{~h}$ before introduction into liquid nitrogen, and aliquots were cryopreserved for later study.

Reagents and monoclonal antibodies - The mouse anti-human surface antigen mAbs used in this study included either FITC-, PE or Cycrome (Cy)-conjugated with: anti-CD8 mAb (IgG1, clone DK25), anti-HLA-DP, DQ, DR $\mathrm{mAb}$ (IgG1, clone CR3/43), anti-CD29 mAb (IgG2a, clone $\mathrm{K} 20$ ), and anti-CD44 mAb (IgG1, clone DF1485) from DAKO; anti-CD49d mAb (IgG1, clone 9F10), anti-CD11a $\mathrm{mAb}$ (IgG1, clone $\mathrm{HI} 111$ ), and anti-CD3 $\mathrm{mAb}$ (IgG3, clone SP34), from BD Biosciences Pharmingen as well as antiCD54 mAb (IgG1, clone HA58) and anti-CD4 mAb (IgG2a, clone S3.5) from Caltag. Intracellular detection of Tia-1 proteins was performed with unconjugated monoclonal anti-human Tia-1 (IgG1, clone 2G9A10F5) from Coulter (US) plus polyclonal rabbit anti-mouse Ig conjugated to FITC from Dako (cat. \# F0313). For Bcl-2 proteins we used PE-conjugated anti-Bcl-2 mAb (IgG1, clone 100) from Caltag. Matching isotype control for each antibody was included in all experiments.

Extra- and intracellular staining by flow cytometry Cryopreserved PBMCs $\left(10^{7}\right.$ cells $)$ were thawed and divided into aliquots each containing $2 \times 10^{5}$ cells in order to stain for flow cytometry analysis. PBMCs were washed in PBSBSA-NaN ${ }_{3}[\mathrm{PBS}$ pH 7.2, supplemented with $1 \%(\mathrm{w} / \mathrm{v}) \mathrm{BSA}$ (Sigma) and $0.1 \% \mathrm{NaN}_{3}$ (Sigma)] and triple-stained for 30 min at $4^{\circ} \mathrm{C}$ with specific $\mathrm{mAbs}$, described above in dilutions recommended by the manufacturer. Stained cells were then washed in PBS-BSA-NaN 3 and fixed in PBS-BSA$\mathrm{NaN}_{3}$ containing $1 \%$ paraformaldehyde (PFA) (Sigma) for $15 \mathrm{~min}$ at $4^{\circ} \mathrm{C}$. Fixed cells were then immediately applied to a FACSCalibur (BD Biosciences).

The intracellular expression of Tia-1 and Bcl-2 proteins was analyzed on thawed PBMC. Cells were quickly first co-stained with PE-conjugated anti-CD4 and Cy-conjugated anti-CD8 mAbs, washed twice with PBS-BSA$\mathrm{NaN}_{3}$ and then fixed with PBS-BSA-NaN ${ }_{3}$ containing $1 \%$ PFA. These cells were washed twice in cold PBS prior to permeabilization by saponine $0.05 \%$ (w/v) (Sigma) for 5 min at room temperature. PBMCs were stained with unconjugated anti-Tia- $1 \mathrm{mAb}$ in $0.05 \%$ saponine buffer for $45 \mathrm{~min}$ at $4^{\circ} \mathrm{C}$. Cells were washed once in PBS then stained with FITC-conjugated anti-mouse and finally fixed in $1 \%$ PFA. PBMCs, pre-stained with Cy-conjugated antiCD8 and FITC-conjugated anti-CD4 were fixed, permeabilized and then co-stained for $45 \mathrm{~min}$ with PE-conjugated $\mathrm{Bcl} 2 \mathrm{mAb}$ as previously described. For each sample, 10,000-20,000 events were acquired, and analyses were performed with the WinMDI 2.8 and FlowJo version 4.3 software.

Cytokine detection assays - Plasma samples were obtained from 43 dengue patients and 15 controls stored in aliquots at $-70^{\circ} \mathrm{C}$ until use. Levels of soluble factors were determined by ELISA kits (R\&D Systems) in compliance with manufacturer's directions. The limits of sensitivity for TGF- $\beta 1$, IL-18 and SICAM-1 were 25.6, 31.2 and 2.47 $\mathrm{pg} / \mathrm{ml}$, respectively.

Statistical analysis - The non-parametric MannWhitney U was used to evaluate variations in the expression of cell surface markers between patients and control donors. $P$ values lower than 0.05 were considered to be associated with statistical significance. Correlation between cell surface marker expression and cytokine production was estimated by Spearman regression analysis. The Prism 4 statistics program was used for all analyses (GraphPad, US).

\section{RESULTS}

$T$ lymphocyte subsets and clinical characterization of adult Brazilian patients with dengue disease - Leukopenia was present in $64 \%$ and thrombocytopenia in $47 \%$ of investigated dengue patients. Most patients, compared to controls, presented a significantly reduced mean percentage of CD4 T lymphocytes during acute phase of infection, which did not return to normal in convalescence days studied (sample up to study day 11 to 30). There were no significant differences in the mean percentage of CD8 T cells between dengue patients during acute or convalescence phases and control individuals. Strikingly, both absolute CD4 and CD8 T cell counts decreased in dengue patients when compared to controls (Table I). In addition, there was no significant difference in CD4/CD8 ratios (controls $1.7 \pm 0.3$, days $1-101.5 \pm 0.75$ and days $>111.7 \pm 0.8$ ).

Among 44 patients with DENV-1, 10 were classified as secondary infection, and among 16 patients with DENV3, 9 were considered secondary infection. We suspect that the in general secondary infections may be more serious than primary and also that DENV-3 is more severe than DENV-1. However our statistical analysis did not confirm this hypothesis. Either severe patient sampling was not big enough to permit group subdivisions or the less frequent incidence of severe cases in primary infection/DENV-1 would hide this effect.

Predominance of activated and cytotoxic CD8 T lymphocytes in dengue patients - We evaluated the degree of activation and cytotoxic capability of T lymphocytes in the course of dengue disease. The mean percentage of CD8 T lymphocytes expressing human leukocyte antigens grouped as class II MHC genes (HLA- DP, DQ, DR) (Fig. 1A, B) or intracellular cytotoxic granule (Tia-1) among total CD8 T lymphocytes (Fig. 1C, D) was significantly higher in dengue patients during 1-10 days after disease onset as compared to that of healthy individuals (values for HLA class II expression among CD8 T lymphocytes: $5.8 \pm 4.0 \%$ on controls vs $15.2 \pm 10.4 \%$ at days $1-10$ vs 7.5 $\pm 4.2 \%$ at $>11$ days and for Tia- 1 expression among CD8 T lymphocytes: $6.6 \pm 6.1 \%$ on controls vs $20.3 \pm 16.1 \%$ at days $1-10$ days vs $4.9 \pm 5.1 \%$ at $>11$ days). Besides each illustration we presented the respective isotype control demonstrating the labelling specificity. There was no significant increase of these activation molecules among CD4 $\mathrm{T}$ lymphocytes (data not shown). In view of the key role of CD8 T lymphocytes in the course of viral infections, 
TABLE I

Clinical features of dengue patients included in the study

\begin{tabular}{|c|c|c|c|}
\hline & Controls & DENV 1-10 & DENV $>11$ \\
\hline Number of samples & 13 & 76 & 12 \\
\hline $\begin{array}{l}\text { Laboratory findings } \\
\text { Hematocrit }(\%) \\
\text { Leukocytes }\left(\text { counts } / \mathrm{mm}^{3}\right) \\
\text { Platelets }\left(\text { counts } \times 10^{3} / \mathrm{mm}^{3} \text { ) }\right.\end{array}$ & $\begin{aligned} 38 & \pm 2^{a} \\
5826 & \pm 1281 \\
271 & \pm 36\end{aligned}$ & $\begin{aligned} 42 & \pm 3.7 \\
3913 & \pm 1680 * b \\
152 & \pm 59 * * *\end{aligned}$ & $\begin{aligned} 40.8 & \pm 2.8 \\
8033 & \pm 4045 \\
245 & \pm 97\end{aligned}$ \\
\hline $\begin{array}{l}\text { Immunological parameters } \\
\mathrm{CD}^{+} \mathrm{CD} 3^{+} \mathrm{T} \text { lymphocytes }(\%) \\
\mathrm{CD} 4 \mathrm{~T} \text { lymphocytes }\left(\text { counts } / \mathrm{mm}^{3}\right) \\
\mathrm{CD} 8^{+} \mathrm{CD} 3^{+} \mathrm{T} \text { lymphocytes }(\%) \\
\mathrm{CD} 8 \mathrm{~T} \text { lymphocytes }\left(\text { counts } / \mathrm{mm}^{3}\right)\end{array}$ & $\begin{aligned} 46.2 & \pm 5.3 \\
513.1 & \pm 134.7 \\
27.9 & \pm 3.5 \\
304.8 & \pm 69.2\end{aligned}$ & $\begin{aligned} 37.6 & \pm 10.2 * * \\
247 & \pm 185.8 * * * \\
26.8 & \pm 8.8 \\
190.7 & \pm 180 * * *\end{aligned}$ & $\begin{aligned} 38.2 & \pm 5.5^{* *} \\
318.2 & \pm 176.5^{* *} \\
24.9 & \pm 5.9 \\
203 & \pm 115\end{aligned}$ \\
\hline
\end{tabular}

$a$ : average \pm standard deviation from patient and control determinations; $b$ : statistical significance was assessed by the MannWhitney $\mathrm{U}$ test to evaluate differences in T lymphocytes between dengue patients and controls; $P$ values: $* \mathrm{p}<0.05, * * \mathrm{p}<0.01$, $* * * p<0.0001$.

A

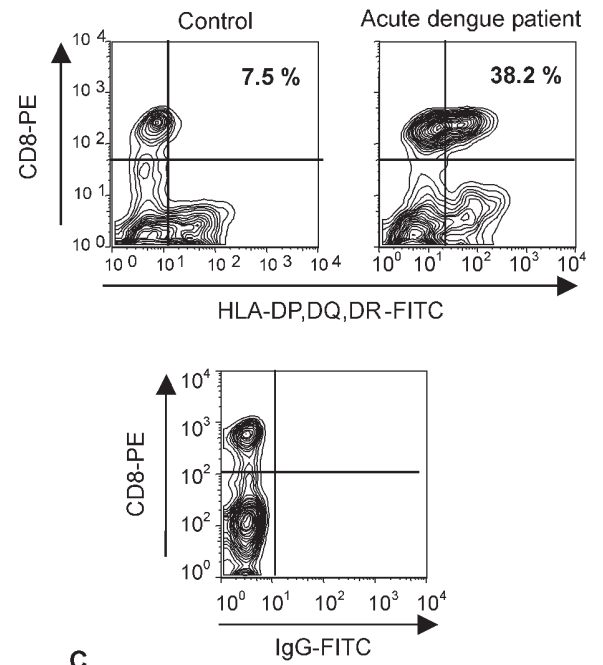

B

HLA-DP,DQ,DR+ among CD8 ${ }^{+}$T cells
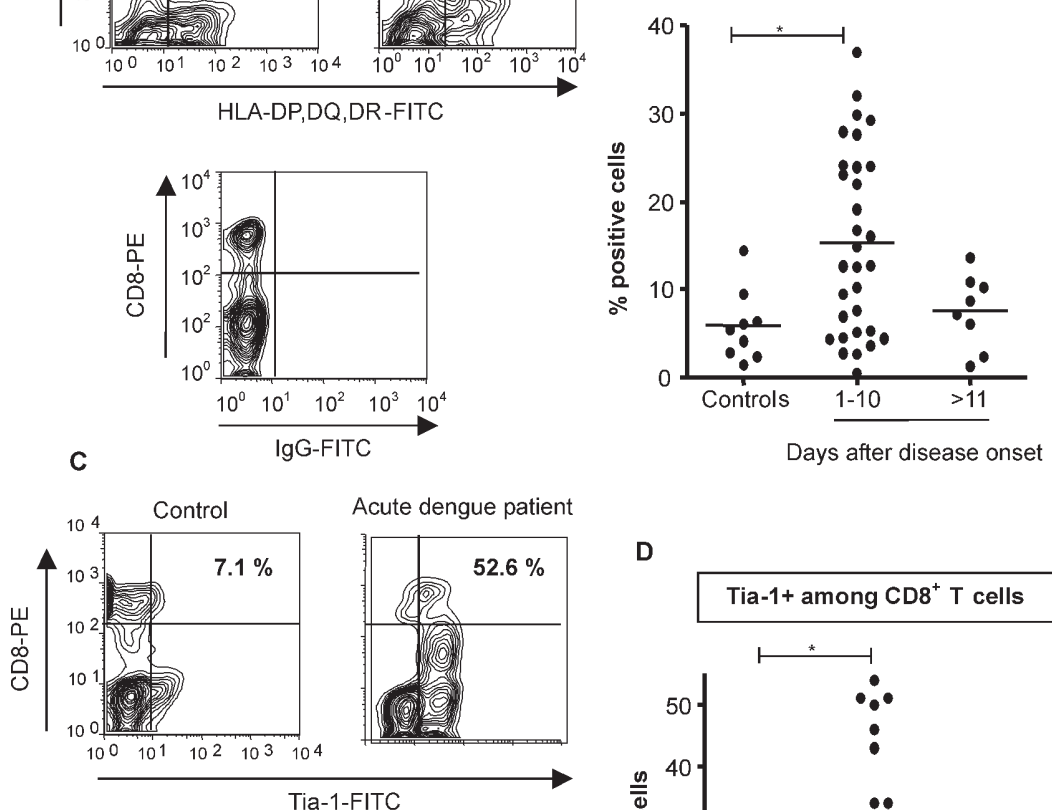

D
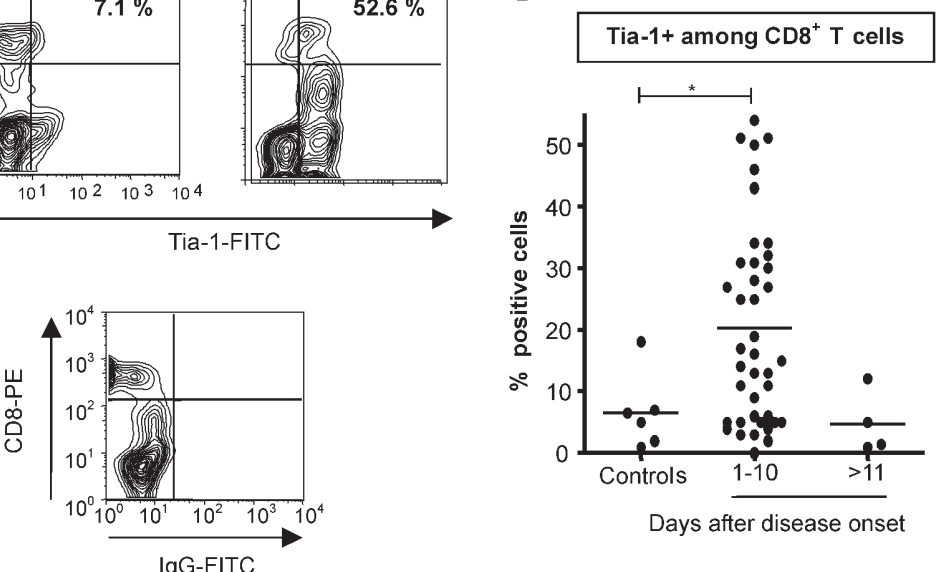

Fig. 1: activation of CD8 T lymphocytes during dengue disease. Peripheral blood mononuclear cells from healthy subjects $(\mathrm{n}=9)$ or samples from dengue patients taken at different time after disease onset: at acute $(1-10$ days, $\mathrm{n}=31)$ and convalescent phase (after 11 days, $\mathrm{n}=8$ ) were labelled as described in Materials and Methods and analyzed by flow cytometry within lymphocyte gate. Representative contour plots of CD8 T cells from a control donor, a dengue patient at day 5 and its respective isotype control are shown demonstrating the labelling specificity. Numbers in each quadrant indicate the percentage of A: HLA-DR, DP, DQ+ or C: Tia-1+ cells within CD8 subsets. Mean percentages of B: HLA-DR, DP, DQ+ or D: Tia-1+ cells among CD8 T lymphocytes are shown for each patient and controls. Statistical significance was assessed by the Mann-Whitney $\mathrm{U}$ test and $*$ represent $\mathrm{P}<0.05$. 
the following analysis was designed to provide additional knowledge of the role mediated by these cells during DENV infection.

Adhesion molecules are up regulated mainly in dengue patient CD8 T lymphocytes - We evaluated the expression of molecules known to mediate adhesive interactions among lymphocytes, endothelial cells and matrix proteins, including VLA-4 (CD49d/CD29), ICAM-1 (CD54), and LFA-1 (CD11a/CD18) (Fig. 2). Initially, we regarded the co-expression of CD49d and CD29 ( $\alpha 4 \beta 1$ integrin, VLA4 ) on $T$ lymphocytes from our study groups. There were significant increases in the mean percentage of CD4 and CD8 Tlymphocytes expressing the VLA-4 and LFA-1 (values for LFA-1 expression among CD4 T lymphocytes: 31,3
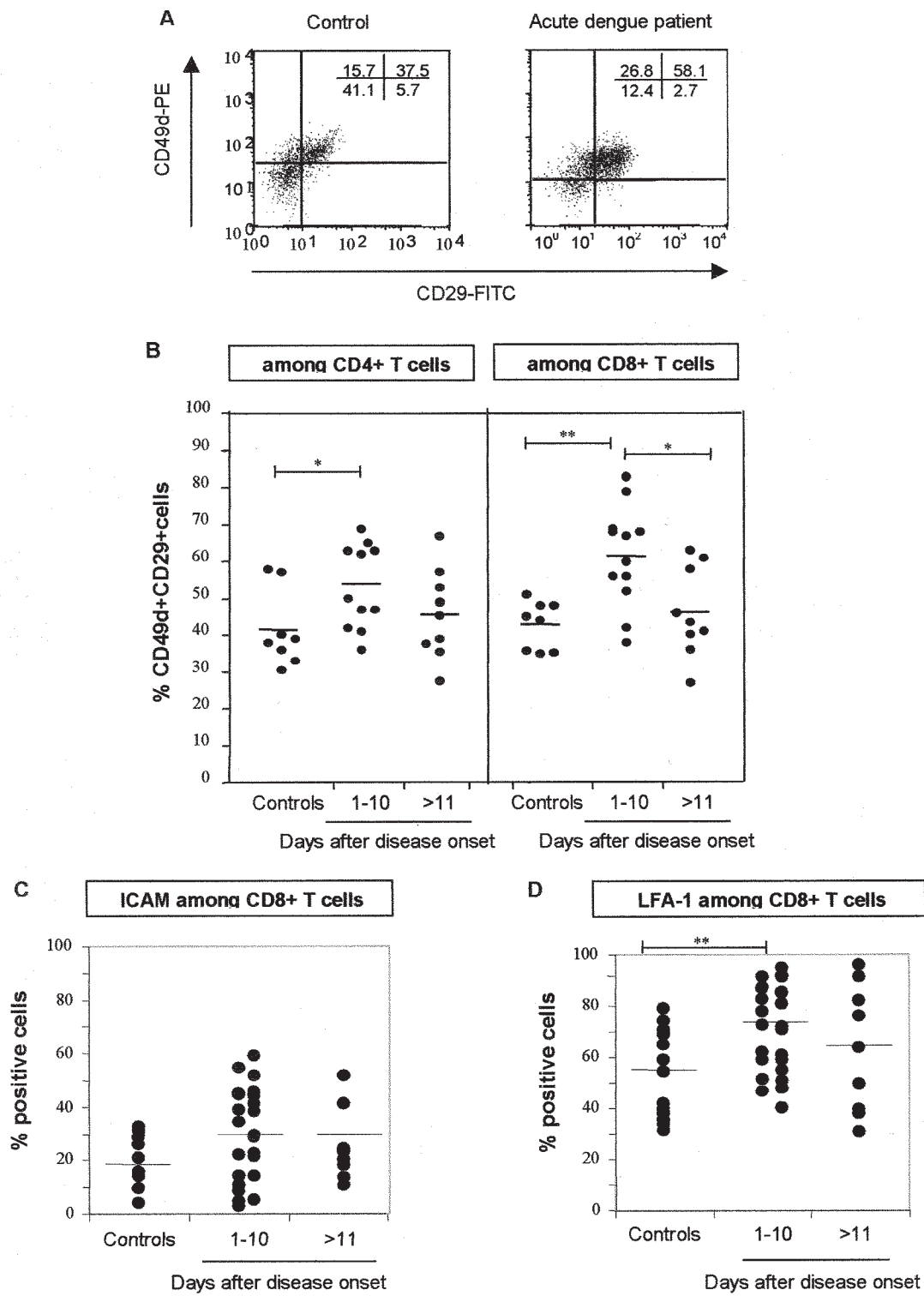

Fig. 2: CD8 T lymphocytes from dengue patients expressing adhesion molecules during acute phase of disease. Peripheral blood mononuclear cells from healthy subjects $(n=12)$ or for samples from dengue patients taken at different periods after disease onset: at acute $(1$ 10 days, $\mathrm{n}=26$ ) and convalescent phase (after 11 days, $\mathrm{n}=10$ ) were labelled as described in Materials and Methods and analyzed by threecolour flow cytometry for particular adhesion molecule expression in CD4 and CD8 T cells. A: ex vivo co-expression of CD49d and CD29 on CD8 T lymphocytes was illustrated from a representative healthy control and a dengue patient with acute infection. B: mean percentages of CD49dCD29 (VLA-4) among CD4 and CD8 T lymphocytes; C: ICAM-1 or D: LFA-1 among CD8 T lymphocytes are show in dengue patients and controls. Statistical significance was assessed by the Mann-Whitney U test.

Values for VLA-4 expression among CD4 T lymphocytes - Controls $41.3 \pm 10 \%$, dengue patients at 1-10 days $54 \pm 11.2 \%$, and patients at $>11$ days $45.6 \pm 12.2 \%$ (controls vs acute dengue patients, $p=0.0136$ in Mann-Whitney U test). Values for VLA-4 expression among CD8 T lymphocytes: controls $42.7 \pm 6.5$, dengue patients at $1-10$ days $61 \pm 13.2 \%$ and patients at $>11$ days $46.1 \pm 12.1 \%$ (controls vs acute dengue patients, $\mathrm{p}=0.0038$ and acute vs convalescent dengue patients $\mathrm{p}=0.0308$ ).

Values for ICAM-1 expression among CD8 T lymphocytes - Controls $18.8 \pm 8.9$, dengue patients at $1-10$ days $29.8 \pm 16.9 \%$, and dengue patients at > 11 dpi $23.1 \pm 13.2 \%$.

Values for LFA-1 expression among CD8 T lymphocytes - Controls $52.9 \pm 17.2$, dengue patients at 1-10 days $71.4 \pm 16.3 \%$ and dengue convalescent patients at $>11$ days $61.7 \pm 24.3 \%$ (controls vs acute dengue patients, $\mathrm{p}=0.0045$ ). 
$\pm 4.7 \%$ on controls vs $43.4 . \pm 19.9 \%$ at days $1-10, p=0.01$ ) among $\mathrm{T}$ cells from dengue patients 1-10 days after disease onset compared with controls (Fig. 2A, B, D). Although not significant, the mean percentage of CD8 T cells expressing ICAM-1 among total CD8 T lymphocytes 1-10 days after disease onset was higher than those observed in control individuals (controls $18 \pm 8.9$ vs dengue patients days 1-10 29.8 \pm 16.9) (Fig. 2C). ICAM-1 in CD4 T cells was not higher in dengue patients compared to that of control individuals (controls $16.9 \pm 11.1$ vs dengue patients days 1-10 19.8 \pm 17.3 ).

Acute phase of DENV infection display an activation/memory response of both patients' $C D 4$ and CD8 T lymphocytes - The establishment of an effective immune response results in the development of a long-lived memory, which either leads to complete prevention of reinfection or to significant reduction of disease severity. We also examined the generation of $\mathrm{T}$ effector/memory cells during DENV infection. Effector and effector/memory $\mathrm{T}$ cells have a reduced potential for homing to lymph nodes, due to decreased expression of lymph node-homing receptors, such as L-selectin (CD62L), and greater capacity to migrate to inflammation sites, due to CD44 expression.

In the acute phase, CD8 T cells from dengue patients were predominantly effectors or effector/ memory $\mathrm{T}$ cells characterized by $\mathrm{CD} 44^{+} \mathrm{CD} 62 \mathrm{~L}^{\mathrm{LOW} /-}$ expression, while naïve $\mathrm{CD} 8 \mathrm{~T}$ cells, detected by $\mathrm{CD} 44^{-} \mathrm{CD} 62 \mathrm{~L}^{+}$staining, were found in the convalescent phase (Table II). Similar results and comparable kinetics were obtained when CD4 $\mathrm{T}$ cells were examined, suggesting that $\mathrm{CD} 4 \mathrm{~T}$ cells, although reduced, may be effectively participating in the development of an anti-DENV immune response. We also analysed the percentage of naïve and effector/memory $\mathrm{T}$ cells from primary and secondary infected dengue patients, and no statistical correlation was found (data not shown).

Low Bcl-2 levels in T CD8 T lymphocytes of patients in acute phase - Previous studies in HIV-infected patients have demonstrated that in vivo down-regulation of the anti-apoptotic protein $\mathrm{Bcl}-2, \mathrm{Bcl}-2^{\mathrm{LOW}}$ and $\mathrm{Bcl}-2^{\text {INTERME- }}$ DIARY $T$ cells, particularly observed in activated CD8 T cells with effectors and effector/memory phenotypes, are susceptible to apoptosis. In contrast, T cells expressing $\mathrm{Bcl}-2^{\mathrm{HIGH}}$ and the phenotype of naïve quiescent cells are completely resistant to cell death (Boudet et al. 1996). The down-regulation of $\mathrm{Bcl}-2 \mathrm{in}$ DENV-specific CD8 T cell from a DENV-1 case with DHF (Mongkolsapaya et al. 2003) has recently been reported. The majority of CD8 T lymphocytes from healthy donors constitutively express homogeneous (INTERMEDIARY) levels of Bcl-2 whereas CD8 cells from HIV-infected patients either express lower (LOW) or higher (HIGH) levels of Bcl-2 (Boudet et al. 1996). We have investigated the ex vivo levels of the antiapoptotic molecule $\mathrm{Bcl}-2$ in the $\mathrm{T}$ cells of our dengue patients. Fig. 3A displays representative data on the ex vivo expression of intracellular $\mathrm{Bcl}-2$ in gated $\mathrm{CD} 8^{\mathrm{HIGH}} \mathrm{T}$ cells from a control donor, an acute dengue patient (1-10 days after disease onset) and another in convalescent phase (>11 days). Our results to date indicate that dengue patients' CD8 T lymphocytes express significantly lower lev-

\section{TABLE II}

Increased levels of effector/memory circulating CD4 and CD8 T cells during acute DENV infection. A: mean percentages of CD44- ${ }^{-}$D62 $2 \mathrm{~L}^{+}$, representative of naïve T cells and $\mathrm{CD} 44^{+} \mathrm{CD} 62 \mathrm{~L}^{-}$, representative of effector/memory $\mathrm{T}$ cells among CD4 T lymphocytes are show in all groups; B: mean percentages of $\mathrm{CD} 44^{-} \mathrm{CD} 62 \mathrm{~L}^{+}$, representative of naïve $\mathrm{T}$ cells and $\mathrm{CD} 44^{+} \mathrm{CD} 62 \mathrm{~L}^{-}$, representative of effector/memory $\mathrm{T}$ cells among CD8 $\mathrm{T}$ lymphocytes are show in all groups

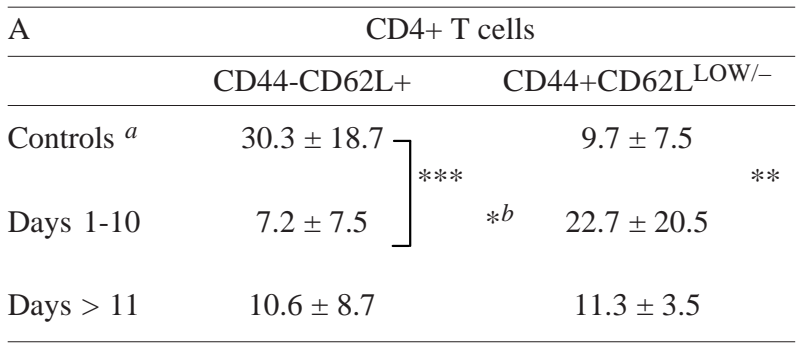

\begin{tabular}{lcc}
\hline B & \multicolumn{2}{c}{ CD8+ T cells } \\
\hline Controls & $20.2 \pm 14.9$ & $* *$ \\
Days 1-10 & $6.5 \pm 6.1$ & $24 \pm 19.8$ \\
Days > 11 & $9.7 \pm 10.5$ & $11.8 \pm 5.6$
\end{tabular}

$a$ : PBMC from healthy subjects $(\mathrm{n}=12)$ or for samples from dengue patients taken at different periods after disease onset: at acute $(1-10$ days, $n=22)$ convalescent phase ( $>11$ days, $n=10)$ were labelled as described in Materials and Methods and analyzed by three-colour flow cytometry for CD44 and CD62L expression in gated CD4 or CD8 T cells; $b$ : statistical significance was assessed by the Mann-Whitney $\mathrm{U}$ test.

els of Bcl-2 during the acute phase as compared to those found in convalescent and healthy donors. This appears to be due to major changes in $\mathrm{Bcl}-2^{\text {INTERMEDIARY }}$ frequency during the acute phase (Fig. 3A, B). In contrast, $\mathrm{CD} 4 \mathrm{~T}$ cells from dengue patients were not altered in their Bcl-2 expression profile (Fig. 3C).

Increased levels of IL-18, TGF- $\beta 1$ and soluble ICAM in the course of dengue disease - The recent findings showed that increased levels of IL-18, TGF- $\beta$, and soluble VCAM-1 in patients with severe dengue disease may in fact be contributing to the pathogenesis of severe DHF (Agarwal et al. 1999, Murgue et al. 2001, Mustafa et al. 2001). Herein, we carried out an ELISA assay in order to investigate the status of IL- 18 , TGF- $\beta 1$, and soluble ICAM1 in the circulation of Brazilian dengue patients grouped depending upon post disease onset time. The data presented in Fig. 4A, B, and C demonstrate that all cytokines studied were present in significantly elevated levels in the plasma of most dengue patients consistent with previous findings in DF and, even more, severe DHF. IL-18 and sICAM- 1 became detectable during the first ten days of illness compared to controls: $282 \pm 234$ vs $59 \pm 18 \mathrm{pg} / \mathrm{ml}$ for IL-18 and $190 \pm 61$ vs $65 \pm 23$ for sICAM-1, and were than diminished to $195 \pm 132$ for IL-18 and $161 \pm 69$ for 
sICAM- 1 on days $>11$. The plasma levels of TGF- $\beta 1$ increased in the acute phase and reached peak levels by day 11 onwards (controls $1888 \pm 1044$ pg/ml, $15107 \pm 10187$ $\mathrm{pg} / \mathrm{ml}$ on days $1-10$ and $27486 \pm 12700 \mathrm{pg} / \mathrm{ml}$ on days > 11).

Correlation between IL-18 with soluble and surface ICAM and percentage T cells expressing HLA-DR among CD8 T lymphocytes - Interestingly, we observed a significant positive correlation between the level of IL-18 in plasma of the dengue patients and the CD8 T cells expressing HLA class II. In addition, levels of IL-18 have been directly correlated with soluble ICAM-1 in plasma and also with CD8 T cells expressing ICAM-1 (Table III). In fact, previous data demonstrated that IL-18 increases the expression of adhesion molecules ICAM-1 and VCAM-1 (Morel et al. 2001), which facilitate the emigration of neutrophils and lymphocytes in containing a $n i$ $d u s$ of infection, thereby contributing to the primary process in inflammatory diseases.

A significant increase of IL-18, TGF-b1, and SICAM1 and activation cell markers on T lymphocytes in severe dengue compared to mild dengue patients - Based on gravity classification, in severe dengue $\mathrm{CD} 4{ }^{+} \mathrm{CD} 3^{+}$and $\mathrm{CD}^{+} \mathrm{CD}^{+}$relative rates and absolute cell counts are not
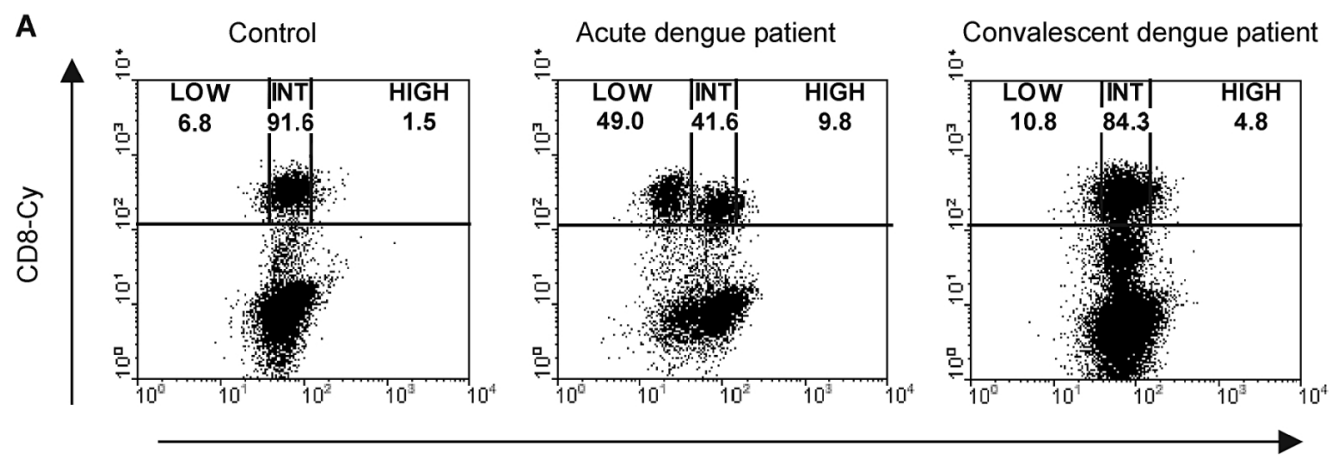

Bcl-2-PE

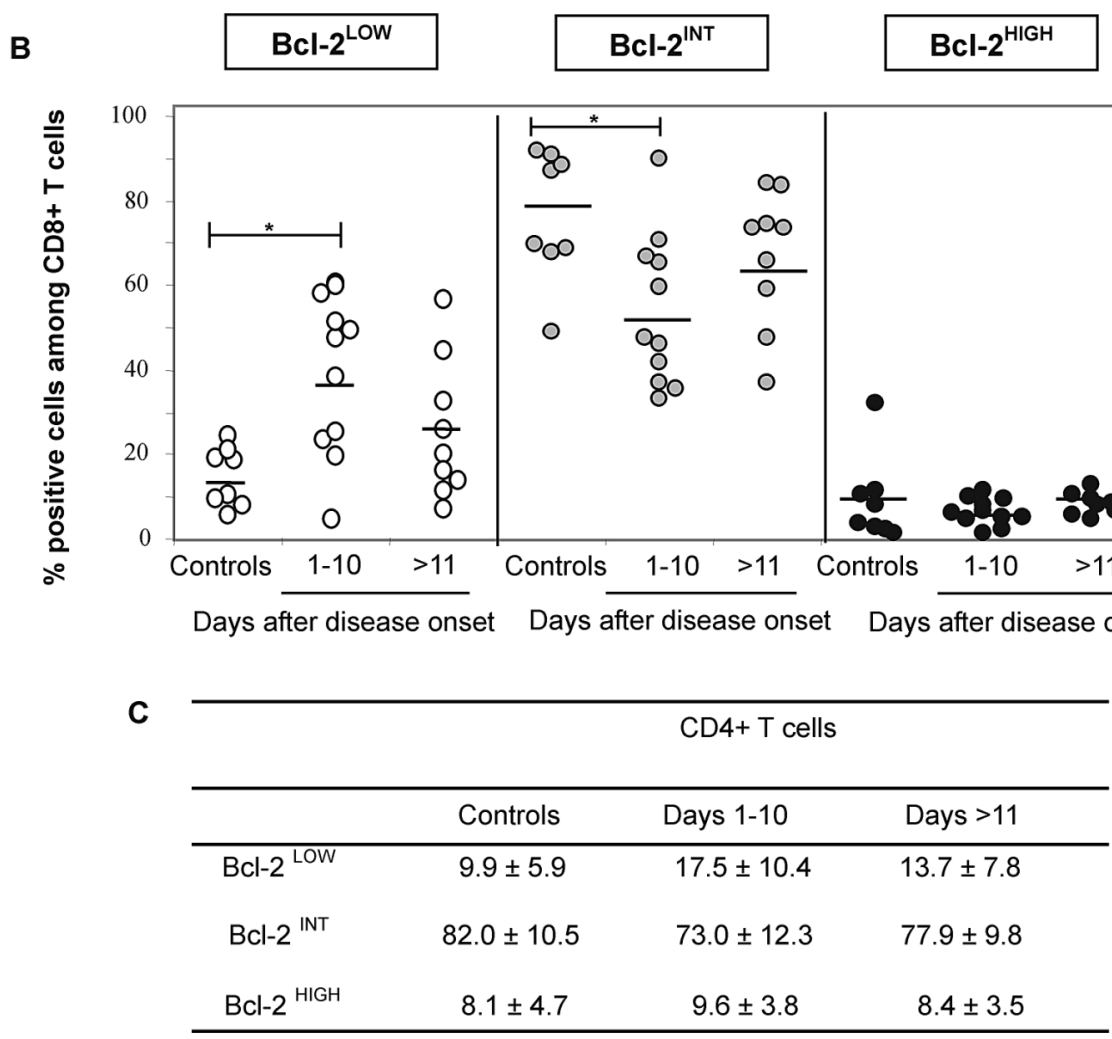

Fig. 3: down-regulation of Bcl-2 expression in CD8 T cells from dengue patients. A: ex vivo expression of Bcl-2 on CD8 T lymphocytes from a representative control and dengue patients during the acute and convalescent phases, respectively. Populations expressing low, intermediary, and high levels of Bcl-2 were determined based in previously report (Boudet et al. 1996). Bcl-2 $2^{\text {LOW }}$, Bcl-2 $2^{\text {INTERMEDIARY }}$ and $\mathrm{Bcl}-2^{\mathrm{HIGH}}$ percentages are indicated within $\mathrm{CD} 8^{\mathrm{HIGH}}$ subset; $\mathrm{B}$ : data represent the $\mathrm{CD} 8 \mathrm{~T}$ lymphocytes differential expressing levels of Bcl-2 of PBMCs isolated from controls $(\mathrm{n}=8)$ and from dengue patients taken at different periods after disease onset: at acute (1-10 days $\mathrm{n}=10)$ and convalescent phases $(>11$ days $\mathrm{n}=9$ ); C: similar analysis was performed by CD4 T lymphocytes. Statistical significance was assessed by the Mann-Whitney U test.

Values for differential expression of Bcl-2 among CD8 T lymphocytes:

Bcl-2 ${ }^{\mathrm{LOW}}$ - Controls $14.0 \pm 7.1 \%$, dengue patients at acute phase $39.4 \pm 18.8 \%$, and at convalescent phase $24.9 \pm 16.5 \%$ (controls vs acute dengue patients, $p=0.0199)$. Bcl-2 $2^{\mathrm{NORMAL}}$ - Controls $76.0 \pm 15.2 \%$, dengue patients at acute phase $54.0 \pm 17.9 \%$, and at convalescent phase $66.5 \pm 15.9$ (controls vs acute patients, $\mathrm{p}=0.0148$ ). $\mathrm{Bcl} 2^{\mathrm{HIGH}}$ - Controls $9.2 \pm 10.1 \%$, dengue patients at acute phase $6.5 \pm 3.0 \%$, and at convalescent phase $8.4 \pm 2.4 \%$. 

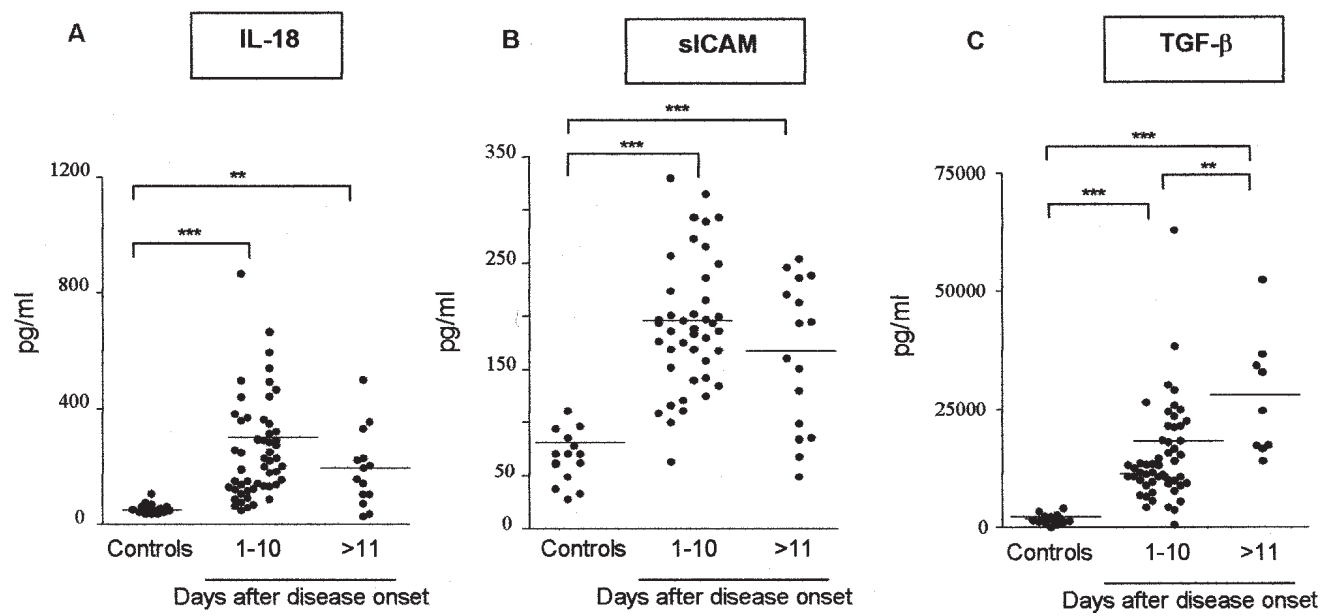

Fig. 4: alterations in IL-18, TGF- $\beta 1$ and sICAM-1 plasma levels during DENV infection. Significant increase in A: IL-18 levels in dengue patients are increased on acute phase (Mann-Whitney U test, $\mathrm{p}=0.0001$ ); B: high levels of sICAM-1 were detected during acute phase of disease $(p=0.0001)$. During convalescence phase of disease, sICAM-1 plasma levels were statistically significantly increased $(p=0.0003)$ when compared to controls; C: TGF- $\beta 1$ plasma levels increased at acute phase, and reached peak levels by day 11 onwards. High levels of TGF- $\beta 1$ were detected during convalescence phase of disease (controls vs dengue patients $p=0.0001$ ) and significantly higher when compared with patients at acute phase $(\mathrm{p}=0.0017)$.

TABLE III

Positive correlation between IL-18 with percent of HLA-DP, DQ, DR, and ICAM-1 among CD8 T lymphocytes and soluble ICAM-1

\begin{tabular}{lccc}
\hline Spearman rank correlation & $r$ & $P$ & $\mathrm{~N}$ \\
\hline HLA class II among CD8 T cells & 0.5140 & 0.0121 & 23 \\
sICAM-1 & 0.4993 & 0.0001 & 66 \\
ICAM-1 among CD8 T cells & 0.7086 & 0.0001 & 25
\end{tabular}

$\mathrm{N}$ : number of samples studied per group.

significantly affected as compared to mild dengue (for CD4 T cells, severe dengue $39 \pm 13 \%$ and $290 \pm 270$ counts/ $\mathrm{mm}^{3}$ vs mild dengue $36.9 \pm 9.3 \%$ and $204 \pm 125$ counts/ $\mathrm{mm}^{3}$ and for CD8 T cells, severe dengue $26.2 \pm 9.4 \%$ and $241.3 \pm 286.8$ counts $/ \mathrm{mm}^{3}$ vs mild dengue $26.7 \pm 8.3 \%$ and $151.4 \pm 107.4$ counts $/ \mathrm{mm}^{3}$ ). Absolute counts of controls were higher for both CD4 and CD8 T cells than mild or severe dengue.

In addition, we investigate whether soluble proteins detected in plasma by ELISA assay and expression of cell activation and/or adhesion molecules on T lymphocytes differs between two dengue patients groups mild and severe in order to and predict gravity of dengue infection disease. Evaluating the whole dengue group we found significantly increased levels of IL-18, TGF- $\beta 1$, and sICAM-1, plasmatic in severe dengue as compared to mild dengue (Table IV). Additionally, expression of HLA-DR, Tia-1 and ICAM-1 in CD8 T cells was higher in severe dengue patients and even more in DHF individuals compared to mild dengue. Moreover, expression of LFA-1 and VLA-4 in CD4 T cells was higher in Severe Dengue patients and even more in a DHF individual compared to Mild dengue (Fig. 5). No differences were encountered between the two groups of dengue in ICAM-1 and LFA1-expressed by CD8 and CD4 T lymphocytes. Moreover, the majority of activation and cell adhesion molecules evaluated were greatly increased in two only DHF patient evaluated.

\section{DISCUSSION}

During the last two decades, incidence of dengue in Brazil has been increasing gradually. In fact, extensive epidemics of DENV 1 and DENV 2 emerged, and after the appearance of DENV 3, recognized in Rio de Janeiro during 2002, the disease became alarming (WHO 2002). It is important to mention that dengue incidence in Brazil occurs mainly in adults while in Asia it is predominantly a paediatric disease. The definition of dengue severity in Latin Americas has often been a matter of debate as severe cases did not satisfy WHO criteria for DHF/DSS. Mainly in Latin American adults, but also in patients from Asian countries, this issue has become striking (Guzman $\&$ Kouri 2003, Phuong et al. 2004). Circulatory collapse is frequently associated with dengue without trombocytopenia or haemorrhagic manifestations. Concerning our patient cohort epidemics in Rio de Janeiro in 2002, most severe cases were associated with shock but without consistent haemorrhagic manifestations. Shock has been considered as high risk even without trombocytopenia (Lum et al. 2002), as registered during several fatal cases in this same Brazilian epidemics (unpublished observations). Harris et al. (2000) classified their patients in Nicaragua in accordance with criteria that did not meet WHO definitions, considering that severe cases with signs of shock need not include trombocytopenia or haemoconcentration. In this context, additional studies in well-characterized patient cohorts from different geographic regions are essential to advance this research and guide new approaches towards prevention and treatment of DHF (Rothman 2004). 
TABLE IV

Association of dengue fever severity with platelets, soluble factors or T cell activation

\begin{tabular}{lcccc}
\hline & Control $(\mathrm{n}=15)^{a}$ & Mild $(\mathrm{n}=31)$ & Severe $(\mathrm{n}=19)$ & Mild vs Severe \\
\hline Platelets $\left(\mathrm{x} 10^{3} / \mathrm{mm}^{3}\right)$ & $271.0 \pm 36.0^{b}$ & $128.0 \pm 29.0$ & $56.0 \pm 20.1$ & $\mathrm{P}<0.0001^{d}$ \\
& & $\mathrm{P}<0.0001^{c}$ & $\mathrm{P}<0.0001$ & $\mathrm{P}<0.0007$ \\
IL-18 $(\mathrm{pg} / \mathrm{ml})$ & $59.0 \pm 18.0$ & $210.0 \pm 189.0$ & $407.0 \pm 284.0$ & $\mathrm{P}<0.0001$ \\
& & $\mathrm{P}<0.0001$ & $20720 \pm 14125$ & $\mathrm{P}<0.0175$ \\
TGF- $\beta 1(\mathrm{pg} / \mathrm{ml})$ & $1888 \pm 1044$ & $11186 \pm 3134$ & $\mathrm{P}<0.0001$ & $\mathrm{P}<0.003$ \\
& & $\mathrm{P}<0.0001$ & $200.0 \pm 53.0$ & $\mathrm{P}<0.0001$ \\
Soluble ICAM-1 (pg/ml) & $65.7 \pm 23.0$ & $149.0 \pm 59.0$ & $20.2 \pm 10.6$ & $\mathrm{P}<0.0265$ \\
& & $\mathrm{P}<0.0001$ & $\mathrm{P}<0.003$ & \\
\hline
\end{tabular}

$a$ : number of subjects studied per group are given in parentheses; $b$ : data are expressed as means \pm standard deviation; $c$ : P values for Mann Whitney U test used to compare different groups vs controls. P values < 0.05 , indicating significant difference; $d$ : P values for Mann Whitney U test used to compare mild vs severe groups.

This one demonstrated significant reduction of circulating $\mathrm{T}$ cells in adult Brazilian DF patients, confirming earlier results (Green et al. 1999a, Liu et al. 2002). Besides reduced CD4 T cell counts, dengue patients displayed a significant decrease in the absolute counts of CD8 T cells compared with that of the healthy controls, consistent with previous observations (Green et al. 1999a, Azeredo et al. 2001). This quantitative alteration on patients' CD8 $\mathrm{T}$ cell counts is a surprising result, since CD $8 \mathrm{~T}$ cells likely play an important role in viral clearance through their ability to produce various factors involved in suppression of viral replication (Guidotti \& Chisari 2001) as well as in cytolysis of virus-infected cells (Carbone et al. 1998). Thus, the clearance of the viral infection probably was not due to increase in cell counts but rather to their activation status, which coincided with the disappearance of virus in circulation.

The evidence for the degree of $\mathrm{T}$ cell activation in dengue patients came from the observation of high expression of HLA-DP, DQ, DR alleles in CD8 T cells during the acute phase but not in CD4 T cells. Such up-regulation is characteristic of T cell activation (Corley et al. 1985). It is widely assumed that clearance of viruses by the immune response requires virus-specific CD8 CTLs that destroy infected cells via cytotoxic granules such as perforin/granzymes or by death receptors and their specific ligand-dependent pathways (Guidotti \& Chisari 2001). Here, we assessed CTL function in vivo in dengue patient cells by the use of a monoclonal antibody that recognizes a $15 \mathrm{kd}$ granule-associated protein (Tia-1) which is restricted to CTLs and NK cells. Unlike healthy controls, patients exhibited a marked increase in the percentage of CD8 T lymphocytes expressing Tia-1, also observed for CTLs isolated from peripheral blood in HIV patients (Tenner-Racz et al. 1993). Although our data does not provide direct evidence that the CD8 T cell subset characterized here consists of DENV-specific CTLs, able to lyse DENV-infected cells, the peak of viremia coincides with the higher expression of Tia-1 among DENV patients' CD8 $\mathrm{T}$ cells. Therefore, the presence of CTLs during DENV early phase infection might play a role in eliminating the virus. Also, the determination of CD8 cytotoxic status among $\mathrm{T}$ lymphocytes during the dengue acute phase is unique, since cytotoxic cells have been detected during only convalescence or later phases.

T cell activation is a critical event for an effective immune response against infection and leads to changes in cell adhesion molecule expression, influencing cell migration and recruitment (Wacholtz et al. 1989). Our results demonstrate for the first time in dengue patients that adhesion molecules such as VLA-4, ICAM-1, and LFA-1 are not only frequently found on CD8 T cells but also on CD4 $\mathrm{T}$ cells during the acute phase of the disease. We propose that the activated cells expressing these molecules are recruited to inflammatory sites and contribute to the inducement of events happening there. It is known that the maintenance of the inflammation depends on the presence of the triggering stimulus. DENV antigens were detected in many tissues obtained from patients with DHF/ DSS (Jessie et al. 2004) and might play a role in providing a chemotactic stimulus to attract activated cells. Cell migration could indicate the progression to clinical severe disease, however we cannot exclude that the generation of effective CTL originating from cells with upregulated cell adhesion molecules could help in the immunoregulatory response against DENV.

We have demonstrated for the first time that during the acute phase both CD4 and CD8 T lymphocytes from dengue patients were predominantly effector or effector/ memory T cells characterized by $\mathrm{CD} 44^{+} \mathrm{CD} 62 \mathrm{~L}^{\mathrm{LOW} /-} \mathrm{ex}-$ pression. In mice a similar cell population of CD8 T cells displays a phenotype $\left(\mathrm{CD} 69^{\mathrm{HIGH}}\right.$, Ly-6A/ $\mathrm{E}^{\mathrm{HIGH}}$, CD62 $\mathrm{L}^{\mathrm{LOW}}$ ) characteristic for effector-memory $\mathrm{T}$ cells observed in brain tissues after dengue infection (van der Most et al. 2003). Thus, additional approaches should be performed in order to evaluate DENV specific immunological memory, considering that induction of memory $\mathrm{T}$ cells is important for an effective DENV vaccine.

Accordingly, the predominance of effector or effector/memory T cells (CD44 ${ }^{+} \mathrm{CD} 62 \mathrm{~L}^{\mathrm{LOW} /-}$ ) in dengue patient 
T lymphocytes studied here was paralleled by significant increase of Bcl-2 $2^{\mathrm{LOW}} \mathrm{CD} 8 \mathrm{~T}$ lymphocytes during the acute phase. Mongkolsapaya et al. (2003) described low levels of Bcl-2 expression and a TUNEL positive reaction (a marker for DNA fragmentation) in DENV-specific CD8 cells during the acute phase in Thai patients. These observations led us to propose that in dengue patients, as in $\mathrm{HIV}^{+}$ patients, there is a relationship between $\mathrm{T}$ cell susceptibility to apoptosis and the activation state. In convalescence, the percentage of effector/memory $\mathrm{T}$ cells is re- established, and Bcl-2 ${ }^{\mathrm{LOW}} \mathrm{CD} 8 \mathrm{~T}$ lymphocytes no longer predominate when viral clearance is achieved ( $>11$ days of infection). In consideration, the lack of physiological protection by $\mathrm{Bcl}-2$ may contribute in vivo with alterations in $\mathrm{T}$ cell homeostasis during DENV infection and/or may constitute an example of primary control of immune response.

In a cohort of dengue patients studied, we observed that in contrast to IL-18 and SICAM-1, which displayed high levels during the early acute phase, TGF- $\beta 1$ was con-
A
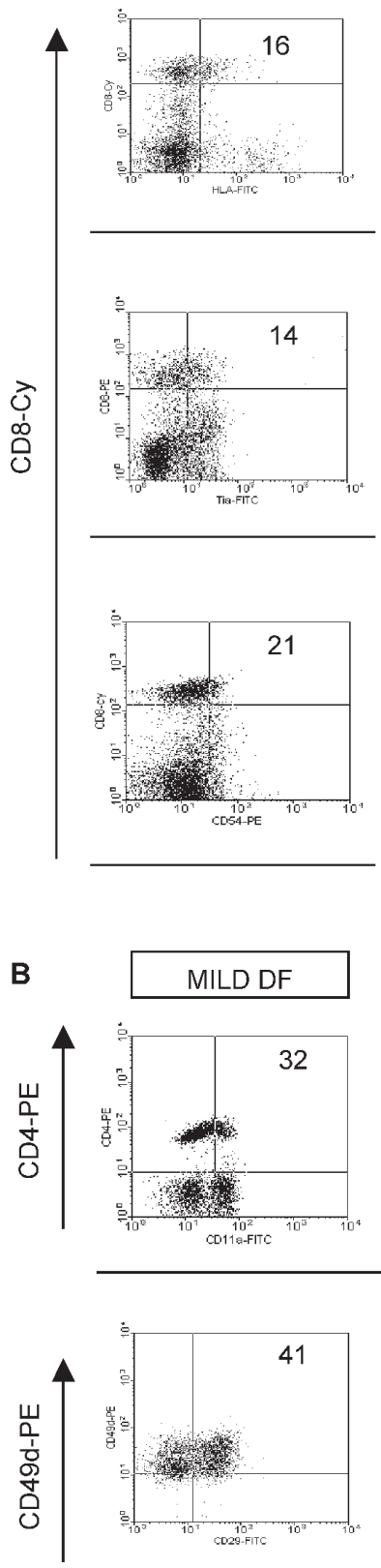

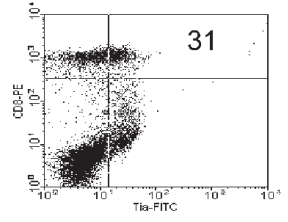

Tia-1-FITC

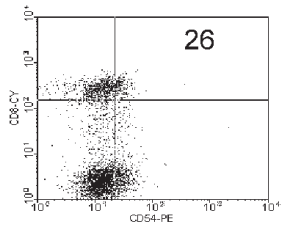

ICAM-1-FITC

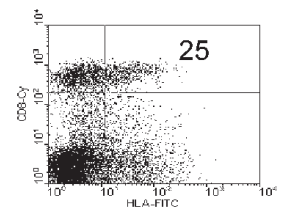

HLA-DR-FITC
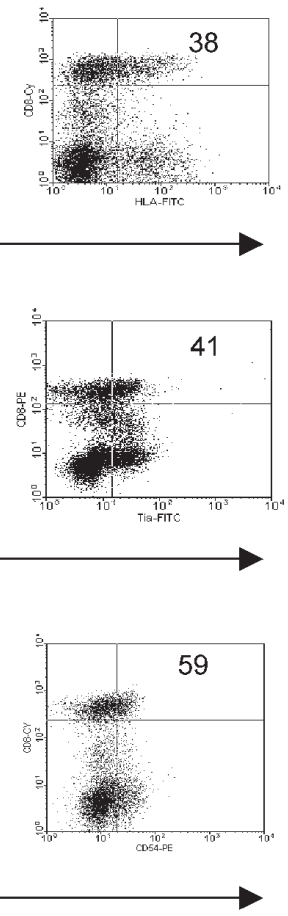

SEVERE DF

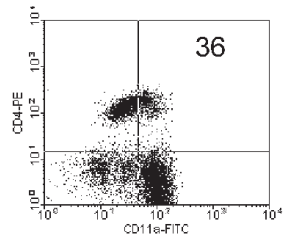

LFA-1-FITC
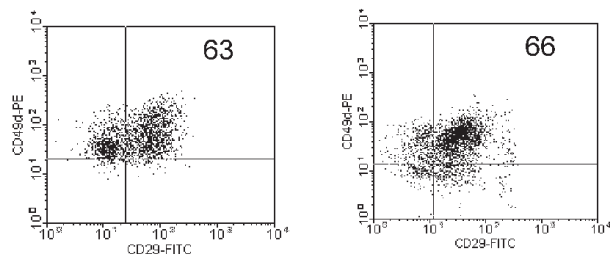

CD29-FITC

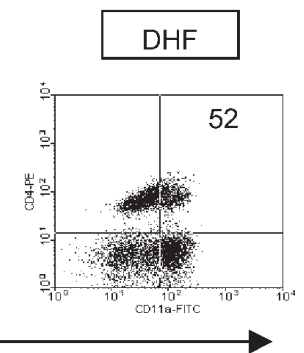

Fig. 5: representative dot plots demonstrating A: CD8 cell frequencies expressing HLA-DP, DQ, DR, Tia-1, ICAM-1; B: CD4 cell frequencies expressing LFA-1 and co-CD49d/CD29 for each individual divided among mild DF, severe DF and DHF. 
siderably more concentrated during the late phases of disease, especially in the convalescence phase. It has been established that soluble factors as chemokines and cytokines act through specific receptors on immune cells to activate and mobilize the response to infection (Harty et al. 2000, Guidotti \& Chisari 2001). However, cytokines exert a double-edge sword function: they are essential for the appropriate function of the immune system but are also potentially toxic mediators of immunopathology under conditions of excess or deregulated production (Slifka $\&$ Whitton 2000). In this context, IL-18 has been reported to be an IFN- $\gamma$ inducer possibly being produced after NK activation and contributing to induce an efficient innate immunity, therefore perhaps stimulating CTL activity in order to achieve viral clearance (Fujioka et al. 1999). On the other hand, IL-18 was associated with pathogenesis in autoimmunity, arthritis, and sepsis, probably by an indirect pathway by inducement of proinflammatory cytokine synthesis (IL-1 and TNF- $\alpha$ ) and chemokines (IL8 and MIP-1 $\alpha$ ) (Dinarello \& Fantuzzi 2003).

Moreover, circulating forms of ICAM-1 were detected in plasma of our dengue patients, as soluble VCAM-1 was encountered in the plasma of children hospitalized for dengue in French Polynesia (Murgue et al. 2001). Circulating forms of adhesion molecules are generally thought to be released from the cell surface by secretion or proteolytic cleavage. They are naturally found in serum of healthy individuals but reach elevated levels in various diseases, such as infections by Plasmodium falciparum, Schistosoma mansoni, HCV and HIV (Jakobsen et al. 1994, Nordoy et al. 1996, Kaplanski et al. 1997).

TGF- $\beta$ has been reported to inhibit many $T$ cell functions, including proliferation and development of cytotoxic cells. However, under certain circumstances, TGF- $\beta$ has also been proved to stimulate $\mathrm{T}$ cells, partly by preventing apoptosis and also inducing $\mathrm{T}$ cell proliferation (Lee \& Rich 1993, Cerwenka et al. 1996). The up-regulation of TGF- $\beta 1$, in late stages of DENV infection might suggest that TGF- $\beta$ activity may suppress the inflammatory response after elimination of DENV and acting in an anti-inflammatory manner in the late steps, prevent possible harm to host by prolonged inflammation.

In accordance with previous studies, when we classified our group of dengue patients based on degree of severity, high levels of IL-18, soluble ICAM-1, and TGF$\beta 1$ were frequently correlated with severe dengue cases. Feasibly elevated levels of soluble ICAM-1 in the plasma of dengue patients might mediate endothelial cell activation and consequently, the plasma leakage phenomenon observed during dengue disease, one of the major hallmarks distinguishing DHF from DF. In fact, it was demonstrated that culture supernatants from DENV infected primary human monocytes could activate endothelial cells by eliciting expression of VCAM-1 and ICAM- 1 in these cells (Anderson et al. 1997). Interestingly, the IL-18 plasma levels were positively correlated with sICAM-1 levels together with the expression of CD54 on T CD8 cells, as described previously that IL-18 increases the expression of ICAM-1 (Morel et al. 2001) and VCAM-1 (Vidal-Vanaclocha et al. 2000), enhancing the recruitment of lymphocytes into inflammatory tissues. Furthermore, our study revealed that $\mathrm{CD} 8^{+} \mathrm{T}$ cells expressing HLA-DR were significantly present in higher frequency in Severe Dengue cases. Although $\mathrm{CD}^{+}{ }^{+} \mathrm{T}$-cell activation might be expected to have an association with a better clinical outcome during viral infections, in long-term HIV-1 infection high levels of cell surface expression of CD38 on CD8 Tcell are instead linked with faster disease progression, in part independent of the predictive value of plasma viral burden and CD4 ${ }^{+}$T-cell number (Liu et al. 1998). More recently, a low $\mathrm{CD} 8^{+} \mathrm{HLA}-\mathrm{DR}^{+}$cell percentage has been considered a significant predictor of immunological longterm HIV disease nonprogressor (ILNTP) status (Paul et al. 2005).

Recently, the phenomenon of "original antigenic sin", first described for B cell responses against influenza virus subtypes (Fazekas de St \& Webster 1966), was observed in dengue infection. Infection with a DENV serotype generated by CD8 $\mathrm{T}$ cells with a higher affinity to a second and presumably previously encountered DENV serotype, leads to the belief that cross-reactive memory CD8 T cells had preferentially expanded over T cells more specific to the serotype causing infection (Mongkolsapaya et al. 2003).

Under the study conditions, immune status activation was found significantly higher in DF patients compared with healthy controls and may allow early assessment of the severity of DF. In fact, the pathophysiological events of dengue disease is frequently associated with high degree of T cell activation, but we cannot exclude a possibility that these activated CD8 T cells identified in DF patients act on infected cells and efficiently clear the virus. The reason why T-cell activation is associated with poor outcome in DENV disease remains unknown. Further additional factors such as immunological exhaustion, hyporesponsiveness of $\mathrm{T}$ cells to their cognate antigens and alterations in the T-cell receptor repertoire must be established in order to evaluate how T-cell activation could be influencing the severity of dengue infection.

\section{ACKNOWLEDGMENTS}

To Dr Marize Miagostovich and Ms Eliana Saraiva for the help during laboratorial diagnosis and the technical support from Ms Mariana Lopes and Ms Maryrose Lavatori. To Dr Joseli Lannes-Vieira, Department of Immunology, Fiocruz, and Dr Ricardo Galler for critically reviewing the manuscript.

\section{REFERENCES}

Agarwal R, Elbishbishi EA, Chaturvedi UC, Nagar R, Mustafa AS 1999. Profile of transforming growth factor-beta 1 in patients with dengue haemorrhagic fever. Int J Exp Pathol 80: 143-149.

Anderson R, Wang S, Osiowy C, Issekutz AC 1997. Activation of endothelial cells via antibody-enhanced dengue virus infection of peripheral blood monocytes. $J$ Virol 71 : 4226-4232.

Azeredo EL, De Oliveira-Pinto LM, Zagne SM, Cerqueira DI, Nogueira RM, Kubelka CF 2006. NK cells, displaying early activation, cytotoxicity and adhesion molecules, are associated with mild dengue disease. Clin Exp Immunol 14: 345356.

Balmaseda A, Hammond SN, Perez MA, Cuadra R, Solano S, 
Rocha J, Idiaquez W, Harris E 2005. Assessment of the World Health Organization Scheme for Classification of Dengue Severity In Nicaragua. Am J Trop Med Hyg 73: 1059-1062.

Boudet F, Lecoeur H, Gougeon ML 1996. Apoptosis associated with ex vivo down-regulation of Bcl-2 and up-regulation of Fas in potential cytotoxic CD8+ T lymphocytes during HIV infection. J Immunol 156: 2282-2293.

Carbone FR, Kurts C, Bennett SR, Miller JF, Heath WR 1998. Cross-presentation: a general mechanism for CTL immunity and tolerance. Immunol Today 19: 368-373.

Cerwenka A, Kovar H, Majdic O, Holter W 1996. Fas- and activation-induced apoptosis are reduced in human $\mathrm{T}$ cells preactivated in the presence of TGF-beta 1. J Immunol 156: 459-464.

Chaturvedi UC, Elbishbishi EA, Agarwal R, Raghupathy R, Nagar R, Tandon R, Pacsa AS, Younis OI, Azizieh F 1999. Sequential production of cytokines by dengue virus-infected human peripheral blood leukocyte cultures. J Med Virol 59: 335-340.

Chen LC, Lei HY, Liu CC, Shiesh SC, Chen SH, Liu HS, Lin YS, Wang ST, Shyu H W, Yeh TM 2006. Correlation of serum levels of macrophage migration inhibitory factor with disease severity and clinical outcome in dengue patients. Am J Trop Med Hyg 74: 142-147.

Corley RB, LoCascio NJ, Ovnic M, Haughton G 1985. Two separate functions of class II (Ia) molecules: T-cell stimulation and B-cell excitation. Proc Natl Acad Sci USA 82: 516520 .

Dinarello CA, Fantuzzi G 2003. Interleukin-18 and host defense against infection. $J$ Infect Dis 187 (Suppl. 2): S370384.

Fazekas de St G, Webster RG 1966. Disquisitions of original antigenic sin. I. Evidence in man. J Exp Med 124: 331-345.

Fujioka N, Akazawa R, Ohashi K, Fujii M, Ikeda M, Kurimoto M 1999. Interleukin-18 protects mice against acute herpes simplex virus type 1 infection. J Virol 73: 2401-2409.

Green S, Pichyangkul S, Vaughn DW, Kalayanarooj S, Nimmannitya S, Nisalak A, Kurane I, Rothman AL, Ennis FA 1999a. Early CD69 expression on peripheral blood lymphocytes from children with dengue hemorrhagic fever. J Infect Dis 180: 1429-35.

Green S, Vaughn DW, Kalayanarooj S, Nimmannitya S, Suntayakorn S, Nisalak A, Lew R, Innis BL, Kurane I, Rothman AL, Ennis FA 1999b. Early immune activation in acute dengue illness is related to development of plasma leakage and disease severity. J Infect Dis 179: 755-762.

Guidotti LG, Chisari FV 2001. Noncytolytic control of viral infections by the innate and adaptive immune response. Annu Rev Immunol 19: 65-91.

Guzman MG, Kouri G 2003. Dengue and dengue hemorrhagic fever in the Americas: lessons and challenges. J Clin Virol 27: 1-13.

Harris E, Videa E, Perez L, Sandoval E, Tellez Y, Perez ML, Cuadra R, Rocha J, Idiaquez W, Alonso RE, Delgado MA, Campo LA, Acevedo F, Gonzalez A, Amador JJ, Balmaseda A 2000. Clinical, epidemiologic, and virologic features of dengue in the 1998 epidemic in Nicaragua. Am J Trop Med Hyg 63: 5-11.
Harty JT, Tvinnereim AR, White DW 2000. CD8+ T cell effector mechanisms in resistance to infection. Annu Rev Immunol 18: 275-308.

Iyngkaran N, Yadav M, Sinniah M 1995. Augmented inflammatory cytokines in primary dengue infection progressing to shock. Singapore Med J 36: 218-221.

Jakobsen PH, Morris-Jones S, Ronn A, Hviid L, Theander TG, Elhassan IM, Bygbjerg IC, Greenwood BM 1994. Increased plasma concentrations of sICAM-1, sVCAM-1 and sELAM-1 in patients with Plasmodium falciparum or $P$. vivax malaria and association with disease severity. Immunology 83: 665-669.

Jessie K, Fong MY, Devi S, Lam SK, Wong KT 2004. Localization of dengue virus in naturally infected human tissues, by immunohistochemistry and in situ hybridization. $J$ Infect Dis 189: 1411-1418.

Kaplanski G, Farnarier C, Payan MJ, Bongrand P, Durand JM 1997. Increased levels of soluble adhesion molecules in the serum of patients with hepatitis C. Correlation with cytokine concentrations and liver inflammation and fibrosis. Dig Dis Sci 42: 2277-84.

Lee HM, Rich S 1993. Differential activation of CD8+ T cells by transforming growth factor-beta 1. J Immunol 151: 668677.

Lin CF, Chiu SC, Hsiao YL, Wan SW, Lei HY, Shiau AL, Liu HS, Yeh TM, Chen S H, Liu CC, Lin YS 2005. Expression of cytokine, chemokine, and adhesion molecules during endothelial cell activation induced by antibodies against dengue virus nonstructural protein 1. J Immunol 174: 395-403.

Liu CC, Huang KJ, Lin YS, Yeh TM, Liu HS, Lei HY 2002. Transient CD4/CD8 ratio inversion and aberrant immune activation during dengue virus infection. J Med Virol 68: 241-252.

Liu Z, Cumberland WG, Hultin LE, Kaplan AH, Detels R, Giorgi JV 1998. CD8+ T-lymphocyte activation in HIV-1 disease reflects an aspect of pathogenesis distinct from viral burden and immunodeficiency. J Acquir Immune Defic Syndr Hum Retrovirol 18: 332-340.

Lum LC, Goh AY, Chan PW, El-Amin AL, Lam SK 2002. Risk factors for hemorrhage in severe dengue infections. J Pediatr 140: 629-631.

Mathew A, Kurane I, Green S, Vaughn DW, Kalayanarooj S, Suntayakorn S, Ennis F A, Rothman AL 1999. Impaired T cell proliferation in acute dengue infection. J Immunol 162: 5609-5615.

Mongkolsapaya J, Dejnirattisai W, Xu XN, Vasanawathana S, Tangthawornchaikul N, Chairunsri, A, Sawasdivorn, S, Duangchinda, T, Dong, T, Rowland-Jones, S, Yenchitsomanus PT, McMichael A, Malasit P, Screaton G 2003. Original antigenic sin and apoptosis in the pathogenesis of dengue hemorrhagic fever. Nat Med 9: 921-927.

Morel JC, Park CC, Woods JM, Koch AE 2001. A novel role for interleukin-18 in adhesion molecule induction through NF kappa B and phosphatidylinositol (PI) 3-kinase-dependent signal transduction pathways. J Biol Chem 276: 37069-37075.

Murgue, B, Cassar, O, Deparis, X 2001. Plasma concentrations of sVCAM-1 and severity of dengue infections. J Med Virol 65: 97-104.

Mustafa AS, Elbishbishi EA, Agarwal R, Chaturvedi UC 2001. 
Elevated levels of interleukin-13 and IL-18 in patients with dengue hemorrhagic fever. FEMS Immunol Med Microbiol 30: $229-233$.

Neves-Souza PC, Azeredo EL, Zagne SM, Valls-de-Souza R, Reis SR, Cerqueira DI, Nogueira RM, Kubelka CF 2005. Inducible nitric oxide synthase (iNOS) expression in monocytes during acute Dengue Fever in patients and during in vitro infection. BMC Infect Dis 5: 64.

Nordoy I, Aukrust P, Muller F, Froland SS 1996. Abnormal levels of circulating adhesion molecules in HIV-1 infection with characteristic alterations in opportunistic infections. Clin Immunol Immunopathol 81: 16-21.

Paul ME, Mao C, Charurat M, Serchuck L, Foca M, Hayani K, Handelsman EL, Diaz C, McIntosh K, Shearer WT 2005. Predictors of immunologic long-term nonprogression in HIVinfected children: implications for initiating therapy. $\mathrm{J} \mathrm{Al}$ lergy Clin Immunol 115: 848-855.

Phuong CX, Nhan NT, Kneen R, Thuy PT, van Thien C, Nga NT, Thuy TT, Solomon T, Stepniewska K, Wills B 2004. Clinical diagnosis and assessment of severity of confirmed dengue infections in Vietnamese children: is the World Health Organization classification system helpful? Am J Trop Med Hyg 70: 172-179.

Rothman AL 2004. Dengue: defining protective versus pathologic immunity. J Clin Invest 113: 946-951.

Slifka MK, Whitton JL 2000. Clinical implications of dysregulated cytokine production. J Mol Med 78: 74-80.

Tenner-Racz K, Racz P, Thome C, Meye, CG, Anderson PJ, Schlossman SF, Letvin N L 1993. Cytotoxic effector cell granules recognized by the monoclonal antibody TIA-1 are present in CD8+ lymphocytes in lymph nodes of human immunodeficiency virus-1-infected patients. Am J Pathol 142: $1750-1758$.

Thein S, Aung MM, Shwe TN, Aye M, Zaw A, Aye K, Aye KM, Aaskov J 1997. Risk factors in dengue shock syndrome. Am J Trop Med Hyg 56: 566-572.

van der Most RG, Murali-Krishna K, Ahmed R 2003. Prolonged presence of effector-memory CD8 T cells in the central nervous system after dengue virus encephalitis. Int Immunol 15: 119-125.

Vaughn DW, Green S, Kalayanarooj S, Innis BL, Nimmannitya S, Suntayakorn S, Endy TP, Raengsakulrach B, Rothman AL, Ennis FA, Nisalak A 2000. Dengue viremia titer, antibody response pattern, and virus serotype correlate with disease severity. J Infect Dis 181: 2-9.

Vidal-Vanaclocha F, Fantuzzi G, Mendoza L, Fuentes AM, Anasagasti MJ, Martin J, Carrascal T, Walsh P, Reznikov LL, Kim SH, Novick D, Rubinstein M, Dinarello CA 2000. IL-18 regulates IL-1beta-dependent hepatic melanoma metastasis via vascular cell adhesion molecule-1. Proc Natl Acad Sci USA 97: 734-739.

Wacholtz MC, Patel SS, Lipsky PE 1989. Leukocyte functionassociated antigen 1 is an activation molecule for human $\mathrm{T}$ cells. J Exp Med 170: 431-48.

Wilder-Smith A, Schwartz E 2005. Dengue in travelers. N Engl J Med 353: 924-932.

WHO-World Health Organization 2002. Communicable Disease Surveillance and Response (CSR) Disease Outbreaks Reported 8 May Dengue/Dengue Haemorrhagic Fever in Brazil - Update 2 http://www.who.int/disease-outbreaknews/n2002/may/8may2002.html. 
